\title{
Selective exploitation of spatially structured coastal fish populations by recreational anglers may lead to evolutionary downsizing of adults
}

\author{
Josep Alós ${ }^{1,2, *}$, Miquel Palmer ${ }^{1}$, Ignacio A. Catalann ${ }^{1}$, Alexandre Alonso-Fernández ${ }^{3}$, \\ Gotzon Basterretxea ${ }^{1}$, Antoni Jordi ${ }^{1}$, Lucie Buttay ${ }^{4}$, Beatriz Morales-Nin ${ }^{1}$, \\ Robert Arlinghaus ${ }^{2,5}$ \\ ${ }^{1}$ Instituto Mediterráneo de Estudios Avanzados, IMEDEA (CSIC-UIB). C/ Miquel Marqués 21, 07190 Esporles, Illes Balears, Spain \\ ${ }^{2}$ Department of Biology and Ecology of Fishes, Leibniz-Institute of Freshwater Ecology and Inland Fisheries, \\ Müggelseedamm 310, 12587 Berlin, Germany \\ ${ }^{3}$ Instituto de Investigaciones Marinas, IIM (CSIC). C/ Eduardo Cabello 6, 36208 Vigo, Pontevedra, Spain \\ ${ }^{4}$ Centro Oceanográfico de Gijón, Avda. Príncipe de Asturias, 70 Bis, 33212 Gijón, Spain \\ ${ }^{5}$ Chair of Integrative Fisheries Management, Faculty of Life Sciences, Humboldt-Universität zu Berlin, \\ Invalidenstrasse 42, 10115 Berlin, Germany
}

\begin{abstract}
When gene flow is limited and harvesting is intensive, fishing may alter life histories and favour trait combinations that collectively reduce adult body size. However, empirical evidence of downsizing of adults in small-bodied coastal fish is still scarce, in part due to the lack of knowledge about the selective nature of certain fishing gears, such as recreational angling, and the difficulties in estimating the dispersion of pelagic early-life stages. Using the small-bodied sedentary coastal marine fish Serranus scriba as a model, we first empirically show that recreational angling selects for life-history traits (i.e. increased reproductive investment) that promote downsizing of adults. Second, using Lagrangian particle dispersion modelling, we show how local hydrodynamics generates patterns of limited connectivity and the emergence of meta-population structure. Finally, the life histories presently observed in isolated populations of $S$. scriba that experienced differential fishing pressure matched expectations of fishing-induced downsizing of adult body size. Body size is an important trait in aquatic food webs, and evolutionary downsizing might have unforeseen consequences. From a precautionary perspective, maintaining the metapopulation structure and the full range of genotypes inherent in them is important, even for smallbodied, geographically restricted fish species that are mainly harvested by recreational anglers.
\end{abstract}

KEY WORDS: Body size $\cdot$ Function-valued approach $\cdot$ Life-history traits $\cdot$ Population connectivity Recreational fishing $\cdot$ Selective fisheries

Resale or republication not permitted without written consent of the publisher

\section{INTRODUCTION}

Exploitation of wild-living animals by humans is often intensive and never random with respect to traits carried by the animal (Allendorf \& Hard 2009). In fact, selective exploitation of species, gender, phenotypes and genotypes is common around the world (Heino \&
Godo 2002, Jørgensen et al. 2007, Allendorf et al. 2008). Elevated and/or non-random harvesting can generate selection responses of certain traits, and result in harvest-induced adaptive changes of lifehistory traits, such as maturation schedule, reproductive investment and growth rate (Jørgensen et al. 2007, Heino et al. 2013, Laugen et al. 2014). Fisheries- 
induced selection should select for fast life histories (Heino et al. 2013) characterised by small size and age at maturation coupled with high reproductive investment, which collectively reduce the individual's adult body size (Law 2000, Jørgensen et al. 2007). Any change in adult fish body size can have negative consequences for the productivity and utility of exploited systems (Jørgensen \& Fiksen 2009, Audzijonyte et al. 2013b, Jørgensen \& Holt 2013). Consequently, knowledge about the selection differentials on life-history traits exerted by fisheries is important for sustainable fisheries management (Arlinghaus et al. 2009).

The potential for fisheries-induced downsizing of body size has been mainly discussed in the context of commercial fisheries, where positive size selection is well documented (Laugen et al. 2014). More complex exploitation patterns with respect to traits selected by fishing are conceivable for passively operated fishing gears (where the odds of capturing a fish depends on a fish's decision to attack and/or ingest baited hooks), such as recreational angling (Uusi-Heikkilä et al. 2008). In many recreational harvesting situations, such as hook-and-line angling, selection of a range of behavioural, physiological and life-history correlated traits is conceivable (Cooke et al. 2007, Uusi-Heikkilä et al. 2008, Philipp et al. 2009, Redpath et al. 2009, 2010, Wilson et al. 2011, Sutter et al. 2012). The resulting complexity of selection pressures on a range of traits that are correlated with the overarching trait 'vulnerability to fishing' suggests that the selection differentials caused by recreational angling may not necessarily show the expected sign. In fact, while negative selection differentials on body size were reported in some recreationally exploited salmonids (Saura et al. 2010, Kendall \& Quinn 2011), the positive correlation between physiological traits, including metabolic rate, metabolic scope, anaerobic capacity or biochemical response to exercise, aggression and vulnerability to fishing may render slow-growing fish more vulnerable to angling gear (Redpath et al. 2009). Therefore, the resulting impact of recreational angling on life histories cannot be easily foreseen (Johnston et al. 2013), and more stock-specific analyses that represent local fishing conditions and patterns are needed (Heino et al. 2013, Laugen et al. 2014). Limited work on fisheries-induced selection pressures on recreationally exploited fish stocks in marine environments exists (Olsen \& Moland 2011).

Besides a detailed knowledge of the selective nature of fishing gear on life-history traits, in open systems, there is a need to consider the dispersal ability of fish if one wants to understand whether the specific life histories observed in the wild are the results of exploitation. Marine environments have been traditionally assumed to operate as systems with high levels of gene flow due the pelagic nature of many early-life stages in a range of species (Roberts 1997). Indeed, gene flow in open marine systems has been identified as a possible mechanism that mitigates fisheries-induced selection pressures from an evolutionary perspective (Olsen et al. 2004, Kuparinen \& Merilä 2007, Dunlop et al. 2009, Pelc et al. 2010). However, coastal currents may create barriers to dispersal (Cowen et al. 2006). Recent studies that combined genetics and oceanography have suggested that marine fish populations are not as open as expected (Palumbi \& Warner 2003, Teacher et al. 2013). Even at spatial scales of a few kilometres, meta-populations with limited gene flow can emerge in the marine environment (e.g. Jones et al. 2005, Carreras-Carbonell et al. 2007, Galarza et al. 2009, Teacher et al. 2013). Indeed, specific oceanic fronts and local hydrodynamic conditions can generate small-scale patterns of isolation within sub-populations in many coastal species, which will increase the vulnerability of local populations to human impacts such as fishing (Galarza et al. 2009, Kough et al. 2013). However, studies matching the selective nature of fishing and the population's connectivity to explain phenotypic life-history variation in the wild are still scarce (Kough et al. 2013).

Capitalising on this idea of matching fishing selection and the structure of the population, we adopted a multidisciplinary approach to provide empirical evidence in relation to whether (1) recreational angling is selective for individual life-history traits, (2) local hydrodynamics plays a role in generating sub-populations exposed to a high level of self-recruitment and limited dispersal and (3) matching the selective nature of recreational angling and the meta-population structure can jointly explain the lower adult body size in heavily exploited marine coastal fish compared to those in protected areas. We used the simultaneous hermaphrodite serranid Serranus scriba in the Mediterranean Sea as a model. S. scriba is a highly sedentary species whose adult dispersions are restricted to few square kilometres (March et al. 2010). The species is heavily exploited by the local recreational angling fishery (e.g. Morales-Nin et al. 2005, Alós \& Arlinghaus 2013). The early-life stages of S. scriba are pelagic and exposed to dispersion following the hydrodynamic conditions of the Mediterranean. Our study was based on a comprehensive analysis of the phenotypic variation of the individual life-history traits in nearby areas at small geographical scales subjected to varying historic fishing pressure com- 
bined with the results from a high-resolution numerical model that allowed estimation of the connectivity of the studied meta-populations. We discuss our results in the context of evolving fish stocks and derive implications for the development of sustainable coastal fisheries.

\section{MATERIALS AND METHODS}

Three lines of evidence were addressed in our attempt to analyse whether selective fishing might contribute to phenotypic variation in the wild. (1) We assessed whether the particular gear under investigation induced selection differentials in reproductive investment and adult body size. (2) We studied evidence of restricted connectivity among local populations. (3) We assessed whether phenotype variations among sub-populations that experienced different selection pressures due to fishing were adequately explained by both processes. We compiled all 3 lines of evidence for Serranus scriba.

\section{Selective effects of recreational angling on life-history traits}

We compared the life history of individuals sampled with an active (experimental beam trawl) and a passive (hook-and-line) sampling method, collected jointly at the same locality and time. We assumed that the experimental beam trawl would capture a greater fraction of the variation in life history present in the fish assemblage than recreational angling. We selected an experimental area of $1.1 \mathrm{~km}^{2}$ corresponding to the average home range of $S$. scriba (March et al. 2010; see Fig. 1). During May at the peak of the spawning season (Alós et al. 2013), S. scriba were sampled using both methods at the same temporal and spatial scale.

The experimental beam trawl was designed for scientific assessment of fish assemblages inhabiting Posidonia oceanica seagrass (see e.g. Moranta et al. 2006, Deudero et al. 2008). The trawl was $3 \mathrm{~m}$ long and $1 \mathrm{~m}$ high. The beam trawl had a net body of $8 \mathrm{~m}$ (1.2 cm square mesh) and a $2 \mathrm{~m}$ long cod end $(0.6 \mathrm{~cm}$ square mesh). The gear was towed over the seagrass for 20 min over a distance of $\sim 900 \mathrm{~m}$. We conducted 3 different fishing hauls using the experimental beam trawl to obtain a sufficient sample size $(n=50$, mean [ $\pm \mathrm{SD}$ ] fish size was $141.8 \pm 26.1 \mathrm{~mm}$, and mean age was $3.6 \pm 1.6 \mathrm{yr}$ ). We also conducted a number of experimental angling sessions in the experimental area to obtain a corresponding hook-and-line sample $(\mathrm{n}=165$, fish size $=144.8 \pm 26.6 \mathrm{~mm}$; and age $=3.59 \pm$ $1.6 \mathrm{yr})$. The experimental angling sessions were conducted following protocols described by Alós et al. (2009). All of the individuals were measured (total length in $\mathrm{mm}$ ) and weighed (total weight in $\mathrm{g}$ ), and their sagittal otoliths were dissected. Additionally, the gonads of a sub-sample of the fish captured using each sampling method (experimental beam trawl: $\mathrm{n}=$ 23 , fish size $=138.6 \pm 32.9 \mathrm{~mm}$, and hook-and-line: $\mathrm{n}=45$, fish size $=146.24 \pm 21.8 \mathrm{~mm}$ ) were used to directly assess the fishes' reproductive investment (batch fecundity) following the method described by Alós et al. (2013). By comparing the life-history traits estimated from individuals sampled by beam trawl and angling, the direction of selection by angling was inferred assuming that the beam trawl captured a more random sample of the population.

\section{Connectivity of Serranus scriba meta-populations that experience differential harvesting pressure}

We explored the possible isolation of some populations of Serranus scriba by analysing the dispersal of early life stages, because dispersal in adult $S$. scriba is negligible (March et al. 2010). Based on these results, we then selected reproductively isolated subpopulations exposed to contrasting contemporary harvesting pressure.

To estimate the degree of sub-population connectivity, we selected 25 areas (see Fig. 1) potentially inhabited by adults of Serranus scriba (any seagrass or rocky bottoms with $<30 \mathrm{~m}$ depth) and estimated the self-recruitment and population connectivity following the procedures of Basterretxea et al. (2012). Briefly, the Lagrangian trajectories (Watson et al. 2011) of weekly releases of passive tracers (virtual eggs) were simulated over a $10 \mathrm{yr}$ period (2000 to 2009 ) in the peak reproductive season (11 wk from April to June). We used a high-resolution (200 m) 3dimensional density-resolving model of the hydrodynamics of the southern Mallorca Island waters, based on the previously validated Princeton Ocean Model (Basterretxea et al. 2012). The real and historical records of flow fields produced by surface wind forcing were obtained from the 12-hourly wind maps from a data-base of 10 yr (Basterretxea et al. 2012).

At the end of the $10 \mathrm{yr}$ simulation, a total of 2125750 virtual eggs and larvae had been tracked up to the end of the pelagic larval duration (PLD), corresponding to the moment of settlement to the seagrass (for Serranus scriba, estimated as 28 d since 


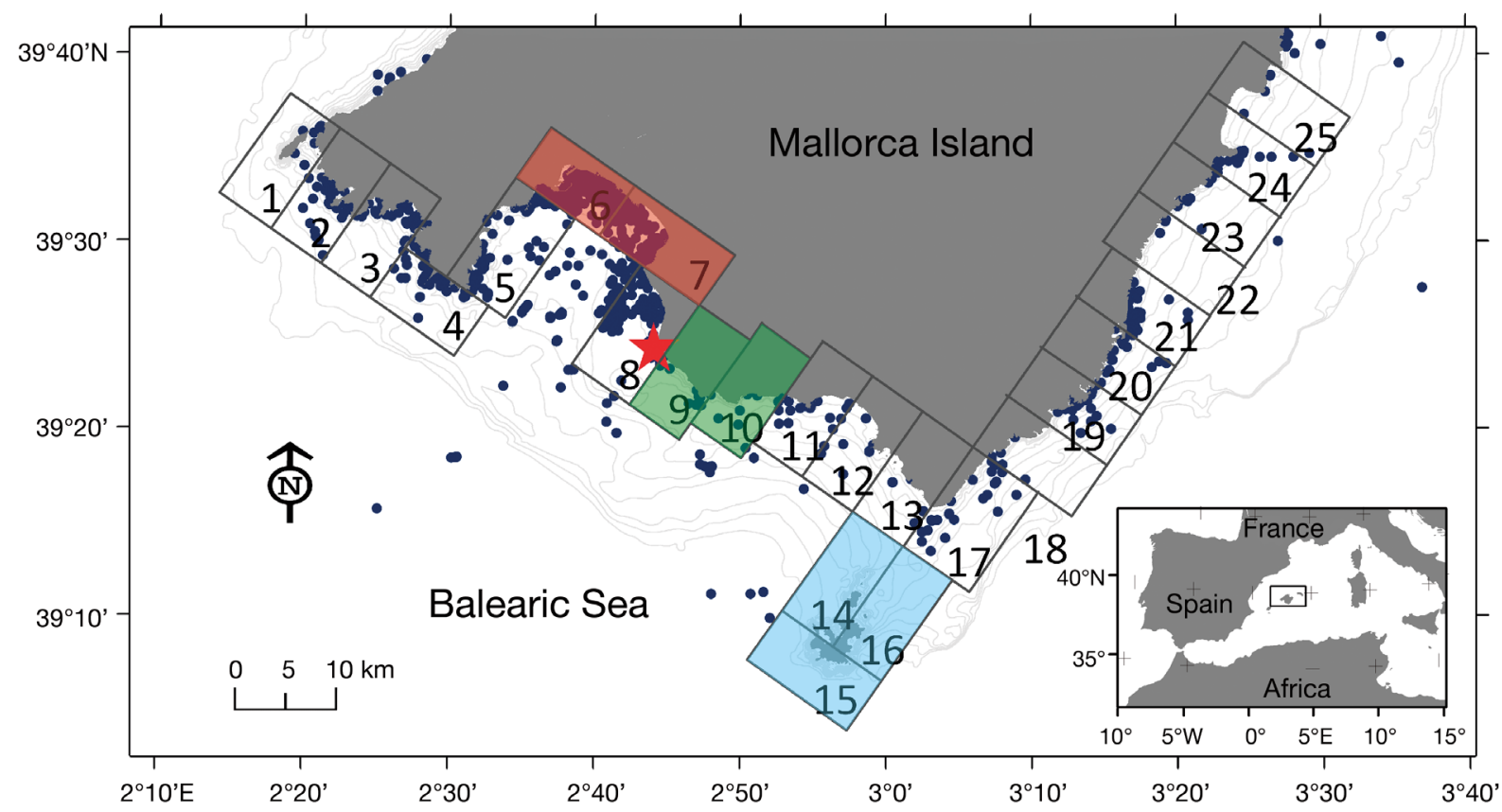

Fig. 1. Mallorca Island in the Balearic Sea (NW Mediterranean) and the location of the 25 sites (delimited by boxes) where virtual eggs were released. Sites 6 and 7 represent the inner region of Palma Bay (in red), Sites 9 and 10 represent the open population (in green), and Sites 14, 15 and 16 correspond to the National Park of Cabrera (in blue). The experiment of harvesting selection (see 'Materials and methods') was performed in the location marked by a red star. Each blue point corresponds to a recreational fishing boat censed in the framework of the research project CONFLICT. Note the large fishing effort concentrated on the inner area of Palma Bay

hatch; Macpherson \& Raventos 2006). The virtual eggs were homogeneously distributed in each area of the top (10 m) layer (see Basterretxea et al. 2012 for further model details). A reflective boundary condition was used to prevent the particles from moving onto land. We assumed individual larvae to have been recruited to a particular area if they were found in the inner-shore habitat (defined by each site) at the end of the PLD. We determined the degree of self-recruitment (mean and SD) defined as the number of particles remaining in area $j$ at the end of the prescribed PLD divided by the numbers of particles initially released in area $j$ in each releasing period (11 wk) (Basterretxea et al. 2012).

The probability that a particle was transported from one area to another by the end of the PLD was considered a measure of direct connectivity. Directconnectivity estimates provide a good indication of the relationship between self-recruitment and dispersal (Basterretxea et al. 2012). However, heritable components of phenotypic variation can also be exchanged through indirect transport involving several generations (Casabianca et al. 2012). We therefore also assessed the indirect connectivity (IC) between paired populations, calculated as follows:

$$
\mathrm{IC}=\sum_{n=1}^{N} D C^{n}
$$

where $N$ is the number of hatching cycles, $D C$ identifies the direct routes, and $D C^{n}$ includes all of the routes requiring $n-1$ steps (or $n$ direct routes). It is important to note that IC conveys a temporal term that provides information about the velocity of the exchange. In the case of phenotypic variation, this definition may be relevant because longer routes of exchange, involving a higher number of generations, may imply loss of the heritable signal (Casabianca et al. 2012).

The results of this simulation experiment showed that the population connectivity of Serranus scriba was dictated by the coastal morphology at the spatial scale we studied (Fig. 2). Two main areas, the inner part of Palma Bay (IPB) and the National Park of Cabrera (NPC), were markedly different from the others, showing the highest degrees of self-recruitment (Fig. 2). In comparison to a control population, which we named open population (OP) (characterized by the average of all other sub-populations in terms of dispersal properties), the final position of the virtual eggs released suggested a notoriously high degree of retention within IPB and NPC (Fig. 3). The correspon- 


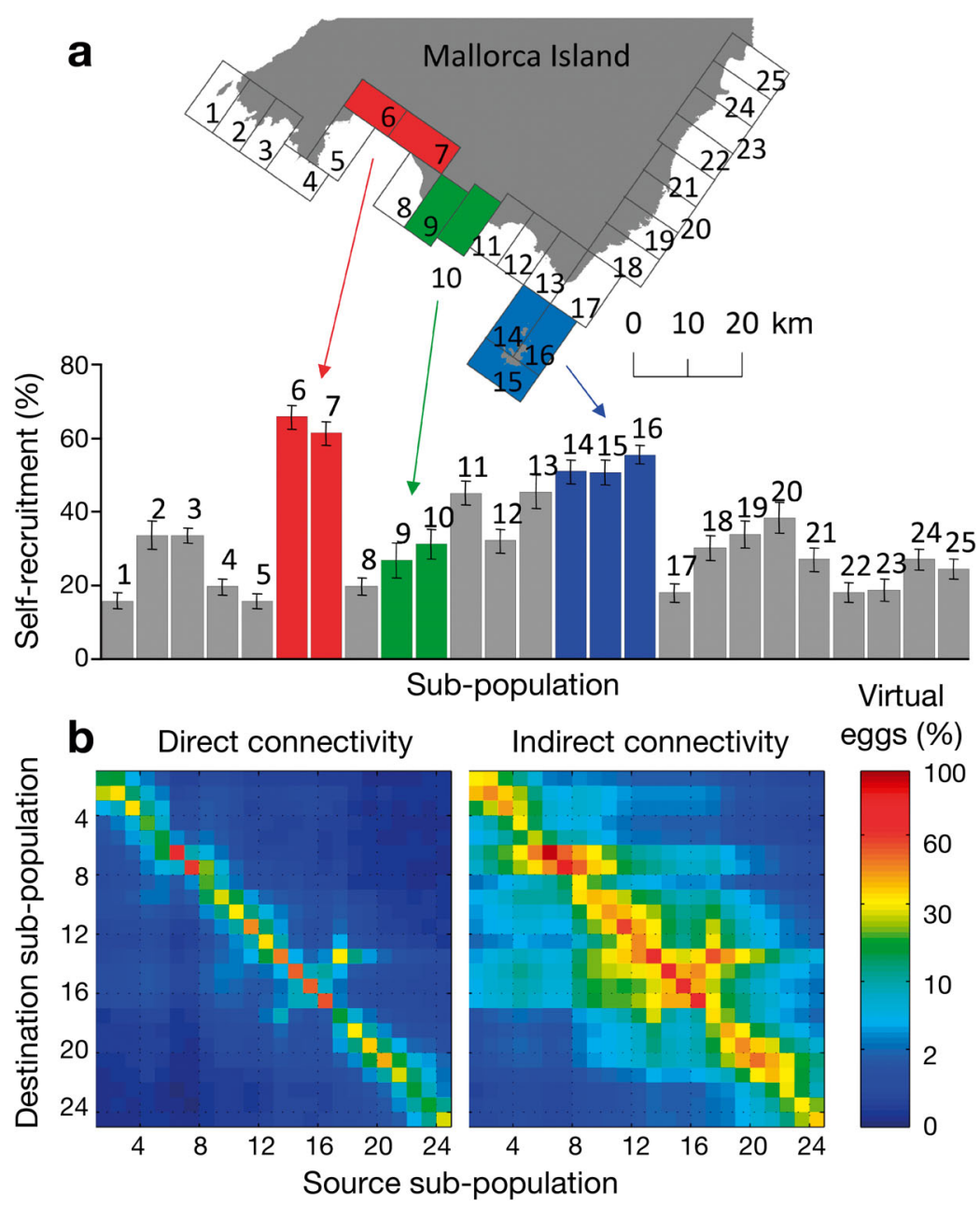

Fig. 2. (a) Local self-recruitment (10 year mean \pm SD) of the 25 populations where virtual eggs were released. Red, green and blue: highest values observed in the inner part of Palma Bay, the open population and the National Park of Cabrera, respectively. (b) 2-paired matrix of direct and indirect connectivity among the 25 sites studied. The scale bar represents the percentage of virtual eggs that moved from one site to another (note that the scale is exponential) and the general limited connectivity among sites

area [MPA]) in 1991 (Francour et al. 2001). Since recreational fisheries were abandoned in NPC, top-predator species and potential predators of small individuals of Serranus scriba have notably increased in abundance (e.g. Epinephelus marginatus; Reñones et al. 1999). In contrast, the IPB hosts the most important recreational angling fishery on Mallorca Island (Cabanellas-Reboredo et al. 2012), and consequently there is substantial recreational fishing effort in this area (see Fig. 1 for the spatial distribution of fishing effort around Mallorca Island). Therefore, we hypothesized that the life-history traits of the actual populations in IPB and NPC should respond to the selective nature imposed by angling or natural mortality and that the life history of $S$. scriba in OP should be intermediate to that in IPB and NPC.

\section{Life history of fish in exploited and unexploited sites}

To test the hypothesis that life history differs in exploited and unexploited sites, we compared the actual status of the populations in terms of average individual life-history strategies in the 3 areas by collecting adult individuals of Serranus scriba from the IPB $(\mathrm{n}=$ 201), OP $(\mathrm{n}=215)$ and NPC $(\mathrm{n}=353)$. The fish sampling was conducted with identical gears (conventional hookand-line; Alós et al. 2009) at areas with

ding direct and indirect (calculated for $50 \mathrm{yr}$ ) connectivities between these 2 population (IPB and NPC) areas were low (Fig. 4), indicating low potential gene flow. These 2 areas also showed a low degree of direct connectivity to the OP (Fig. 4). Therefore, while the populations in the OP were considered to have gene flow, IPC and NPC were considered to be more isolated from each other and from the OP.

Apart from the limited connectivity of NPC or IPB to other areas, these sub-populations were also unique because they were the only sites exposed to the minimum and maximum harvesting selection pressure. These features rendered NPC and IPB unique casestudy candidates to test our hypothesis. The NPC was declared a sanctuary (a no-take marine protected similar habitat characteristics (seagrass meadows of Posidonia oceanica) and depths. Samples were processed as described before. In addition, the gonads from sub-sampled individuals from May and June $(\mathrm{n}=53$ from the IPB, $\mathrm{n}=41$ from the OP and $\mathrm{n}=79$ from the NPC) were used to directly measure reproductive investment. Moreover, in all 3 sites, we assessed the relative abundance of fish (using catch per unit effort as an index) and enumerated the size and age of fish vulnerable to conventional hook-andline gear. Although the relationship between catch rate and abundance is sometimes problematic (Walters \& Martell 2004), catch rate data can serve its purpose in comparative studies when effort is highly standardised and the capture method is replicable, as 

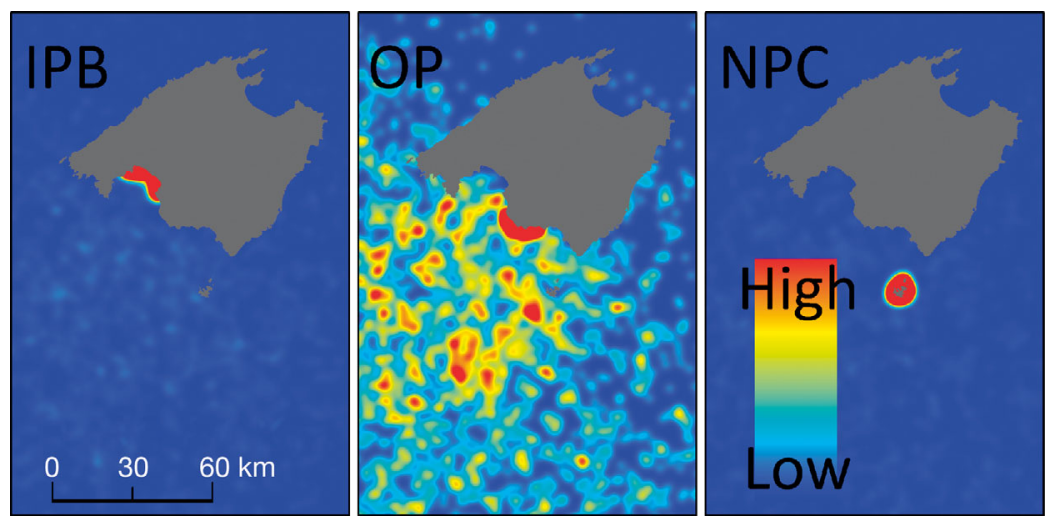

Fig. 3. The spatial plots of fixed kernel probability distributions (kernel density value gradient estimated in a grid of $250 \times 250 \mathrm{~m}$ ) of the positions at the end of the pelagic larval duration of the virtual eggs released in each of the selected main areas: the inner part of Palma Bay (IPB), the open population (OP) and the National Park of Cabrera (NPC)

in our study. We performed experimental fishing sessions (IPB: $\mathrm{n}=54$, OP: $\mathrm{n}=24$, and NPC: $\mathrm{n}=64$ ) using the standardised recreational angling gear described by Alós et al. (2009), visiting each sub-population on randomly selected days during a 1 yr period.

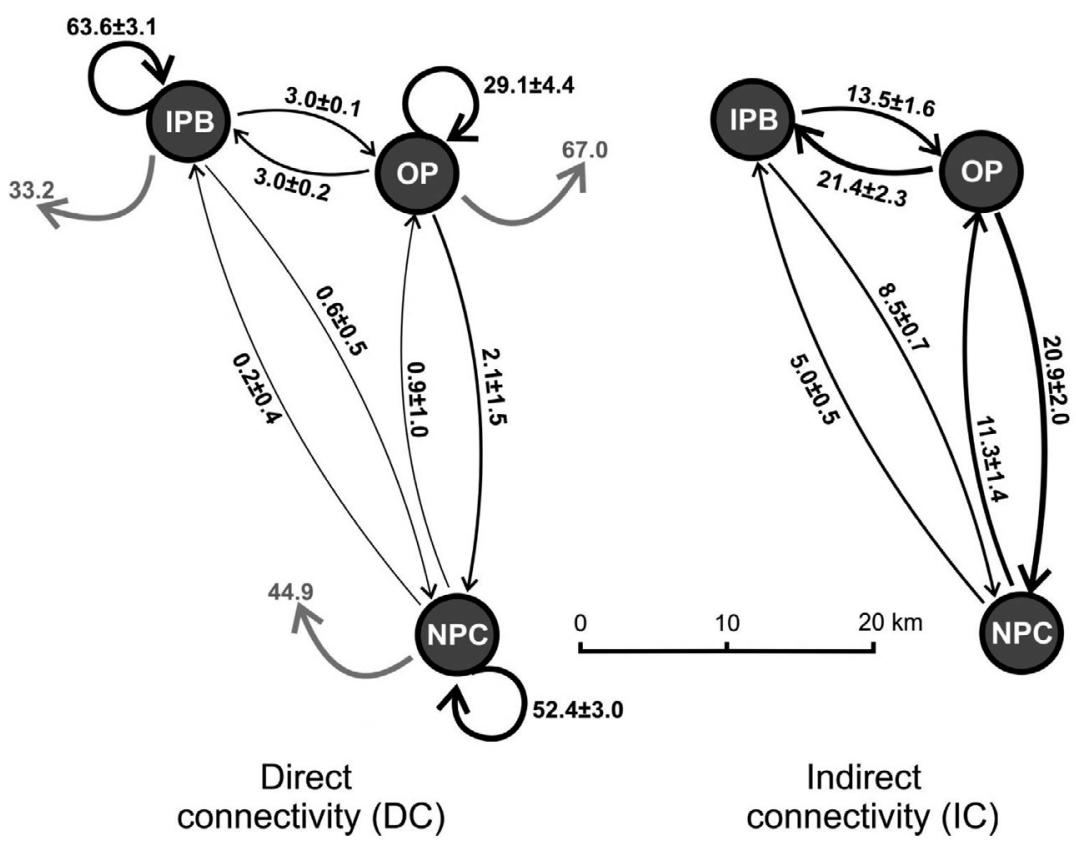

Fig. 4. Directional flow diagram showing the paired direct and indirect connectivity (black arrows) calculated among the 3 sub-populations studied (each number and the thickness of each arrow can be interpreted as the percentage of eggs released in a specific sub-population that recruited in another): the inner part of Palma Bay (IPB), the open population (OP) and the National Park of Cabrera (NPC). Indirect connectivity values are the maximum values of connectivity over a $50 \mathrm{yr}$ period. The grey arrows show the connectivity attributed to other sub-populations. The $360^{\circ}$ black arrows indicate the self-recruitment values for each specific sub-population

\section{Estimation of individual life-history traits of Serranus scriba}

A function-valued approach was chosen to infer key individual life-history traits in which parameters (traits) estimated from individual growth curves were used as data characterising each individual fish (Stinchcombe \& Kirkpatrick 2012). Back-calculation of length-at-age using growth marks contained in otoliths can offer a reliable method to obtain repeated measures of length-at-age over the lifespan of the same individual whenever there is a strong relationship between fish and otolith size (Pilling et al. 2002, Swain et al. 2007, Alós et al. 2010, Mollet et al. 2010, Brunel et al. 2013). We fitted the individual length-at-age data points extracted from the otoliths of $S$. scriba following the protocol by Alós et al. (2010) to the bi-phasic growth model proposed by Lester et al. (2004). This approach allowed us to obtain individual measures of the annual reproduction investment $(g)$, maximum theoretical size $\left(L_{\infty}\right)$, age of initiation of maturation $(T)$ and immature growth rate $(h)$ independently of the fish size at sampling (Shuter et al. 2005, Arlinghaus et al. 2009, Matsumura et al. 2011). The model assumes linear growth in the juvenile phase and a trade-off between the energy allocation to somatic growth and reproduction in the adult ages (Lester et al. 2004). The model developed by Lester et al. (2004) is a special case of a more general version developed by Quince et al. (2008a,b) and is valid for a length-weight relationship with an exponent $b=3$, which is the case for $S$. scriba (Alonso-Fernández et al. 2011).

The somatic growth rate before the age of the onset of maturation ( $T$, years) in the model by Lester et al. (2004) is given as follows:

$$
L_{t}=h\left(t-t_{1}\right)+\varepsilon \quad \text { when } t \leq T
$$

where $L_{t}$ is the length at age $t(\mathrm{~mm}), h$ is the immature growth $\left(\mathrm{mm} \mathrm{yr}^{-1}\right), t_{1}$ is the theoretical age at size $0 \mathrm{~mm}$, and $\varepsilon$ is the Gaussian error. 
When the individual starts investing in reproduction at age $T$, the somatic growth is represented by the von Bertalanffy growth equation with parameters that provide explicit information on the energy allocated to reproduction $\left(g, \mathrm{yr}^{-1}\right)$ as follows:

$$
L_{t}=L_{\infty}\left(1-e^{-k\left(t-t_{0}\right)}\right)+\varepsilon \text { when } t \geq T
$$

where $L_{\infty}=3 h / g$.

These 2 equations provide a biologically meaningful interpretation of the von Bertalanffy growth parameters (Lester et al. 2004). Accordingly, the growth factor $k$ is proportional to the reproductive investment $g$ and reflects the relative investment averaged over the entire reproductive cycle, and $L_{\infty}$ is the ratio of net production to reproductive investment $\left(L_{\infty}=\right.$ $3 \mathrm{~h} / \mathrm{g}$ ), which is representative of the adult body growth (Lester et al. 2004). The growth model was fitted using a hierarchical Bayesian approach for each individual. Two different models were fitted (between fishing methods and between populations).

The model was implemented and run using the runjags library of the R package (www.r-project.org), which opens JAGS (http://mcmc-jags.sourceforge. net). It was fitted for individuals of age $\geq 5$ at capture, which substantially improves the accuracy of the method (Alós et al. 2010, Brunel et al. 2013). Moreover, due the over-dispersed representation of older ages in the unexploited NPC site in the second model, 50 individuals were randomly selected. Using this approach, the ages and the number of observations per individual included in the analysis were not different among samples in the fitting of the first $\left(\chi^{2}\right.$ test, $\mathrm{p}=0.46)$ and second model $\left(\chi^{2}\right.$ test, $\left.\mathrm{p}=0.1\right)$. Therefore, any significant variation in life-history traits among the gears or sites was independent of the fish size at sampling and the number of samples (ages). A hierarchical structure for population and individuals of minimal priors was used (see Supplement 1, www.int-res.com/articles/suppl/m503p219_ supp.pdf). Three Monte Carlo Markov chains (MC$\mathrm{MC}$ ) were run, and the convergence was assessed using a Gelman-Rubin diagnostic (Plummer et al. 2006). The feasibility of the Bayesian framework adopted here was assessed through a simulation analysis (see Supplement 2).

We estimated the direction of selection of recreational angling by comparing the distributions of the individual Bayesian means of each life-history trait for the 2 fish sampling methods (beam trawl and hook-and-line). Subsequently, inter-population comparisons of the average life-history traits were conducted by comparing the Bayesian population means of each life-history trait using Bayesian credibility intervals (BCI) $(2.5$ and $97.5 \%)$. Unlike the frequentist $\mathrm{p}$-value, the Bayesian posterior distributions are interpreted correctly as a belief that there is a given probability that the parameter of interest lies within the interval (Ellison 2004). To make robust conclusions regarding the between-populations differences, we considered differences when the BCI did not overlap at all. $L_{\infty}$ and $h$ were expressed in $\mathrm{mm}$ of otolith, but in some cases, the scale was translated to total length using the regression model provided by Alós et al. (2010) to facilitate interpretation.

Between-gear and between-population differences in the direct measures of reproduction investment (batch fecundity controlled for fish size) and population differences in the relative abundance, age and size of the vulnerable fish sampled by experimental angling were analysed using general linear mixed effects models (GLMM). The models were fitted following a forward step-by-step procedure until maximum explanatory power was reached (Akaike's information criterion) (Zuur et al. 2009). The p-values for each parameter were estimated through MCMC simulations using the library language $R$ of the $\mathrm{R}$ package.

To help identify whether actual life-history traits can be adequately explained by the direction of recreational harvesting and the population's connectivity, we also included ancillary environmental data. A $10 \mathrm{yr}$ record of satellite (MODIS-Aqua)-derived monthly averages of sea surface temperature (SST) and chlorophyll $a$ as a measure of productivity was obtained for each of the 3 sub-populations included in the analyses and compared among them. In both of the cases (temperature and productivity), chronograms were used to visually inspect variation among sites.

\section{RESULTS}

\section{Selection pressures on life history caused by recreational angling}

The average $g$ of the fish vulnerable to hook-andline fishing gear was smaller than that of those captured in the experimental trawl (Table 1). Moreover, the mean of the maximum size $\left(L_{\infty}\right)$ was significantly different between the 2 gears, with larger values found in the hook-and-line individuals compared to fish vulnerable to the beam trawl (Table 1). While the results of the immature growth rate $(h)$ and onset of maturation $(T)$ suggested on average an older age of maturation and smaller immature growth of the hook-and-line individuals compared to the fish vulnerable to trawl, the BCI overlapped notably, sug- 


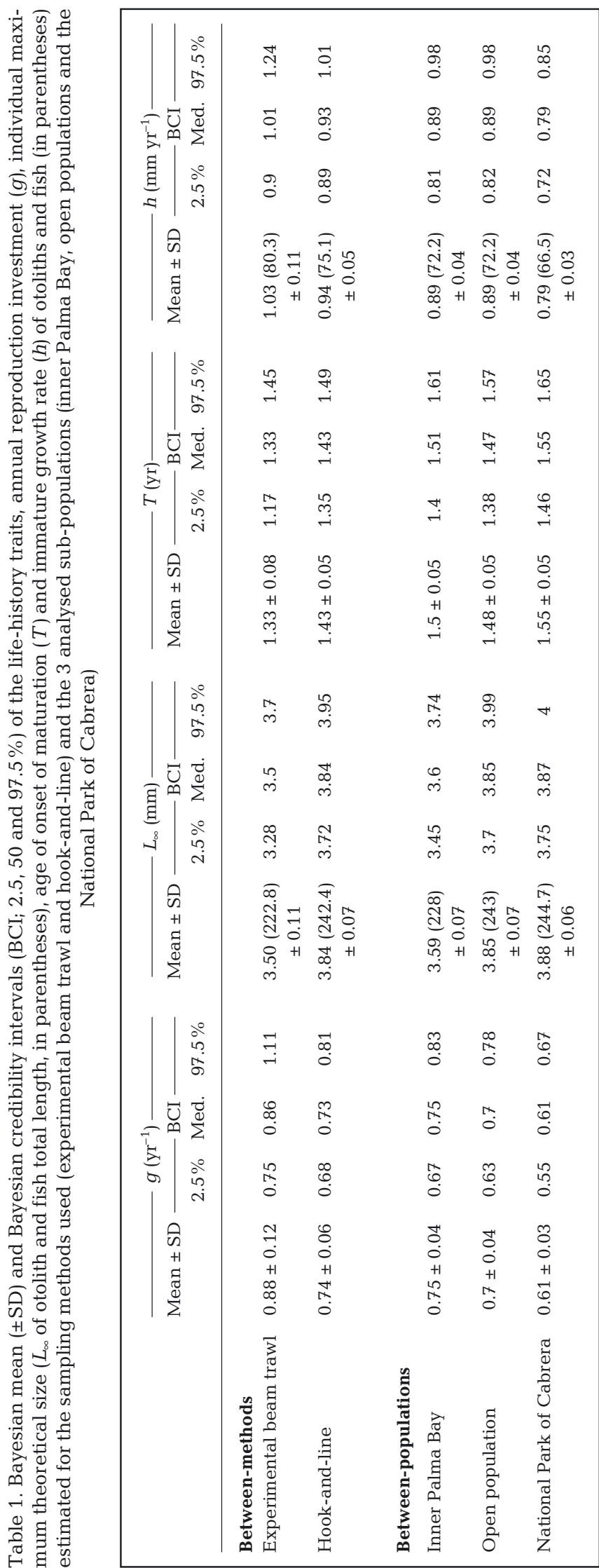

gesting a lower potential for angling-induced selection differentials on these traits (Table 1). A box-plot of the individual values of the life-history traits estimated for the 2 fishing gears revealed directional fishing-induced selection favouring fish with higher reproductive investment and smaller terminal length under conditions of intensive recreational harvesting (Fig. 5). Therefore, the results of our experimental approach demonstrated fishing-induced selection pressures favouring downsizing of adult body length.

The direct measures of reproduction investment (batch fecundity) were in line with those obtained for the indirect measures of $g$ inferred from the growth curves. Accordingly, there were significant differences between the fish caught using a beam trawl and via hook-and-line (GLMM, $\mathrm{p}<0.05$; Table 2): individuals sampled using hook-and-line invested less in reproduction than the trawl-captured fish (Table 2). The relationship between the batch fecundity and $g$ estimated from the growth curve was positive and highly significant (GLM, $\mathrm{p}<0.01$ ).

\section{Sub-population alteration of life history in response to recreational fishing}

The actual wild populations of Serranus scriba mirrored the selective nature of the expected source of mortality (fishing-induced or natural predatorinduced): while a life history characterized by small body adult size was observed in the exploited population (IPB), the opposite was found in the marine protected area (NPC). In the open control area (OP), both life-history strategies were observed. There were non-overlapping posterior distributions of reproductive investment $g$ between the IPB and the NPC (Table 1). Thus, we accepted the hypothesis of higher reproductive investment in the exploited site IPB relative to the unexploited site NPC (Table 1, Fig. 6). By contrast, the posterior distribution of the OP population had intermediate values that notably overlapped with the distributions of the other 2 populations (Table 1). We found differences for $L_{\infty}$ between the Bayesian means of IPB and NPC, indicating a lower final size of the fish living in the exploited site IPB (Table 1, Fig. 6). In the case of $T$ and $h$, the posterior distributions of the 3 populations overlapped, indicating the implausibility that the cause was an adaptive response (Table 1, Fig. 6).

The life-history strategy associated with small (IPB) or large (NPC) adult body size was also confirmed through the direct measure of reproductive investment (batch fecundity). Accordingly, the individuals 
Table 2. Results of the 5 GLMM fitted to test (1) the relationship between the batch fecundity (number of eggs per fish) between (i) the sampling methods and (ii) sub-populations (IPB: inner Palma Bay, OP: open population) and (2) the differences between the (iii) relative abundance (no. of fish collected in $30 \mathrm{~min}$ by angler), (iv) average fish size ( $\mathrm{mm}$ ) and (v) average ages (years) in the sub-populations. The full model for the reproductive investment included fish size and month as fixed factors. In the case of the relative abundance, fish size and age of vulnerable fish, the full model included depth (m), angler, bait and month as fixed factors. In all of the models, fishing session within-day was included as a random factor. The table shows the Monte Carlo Markov chains (MCMC) mean of the parameter, the highest $95 \%$ credibility intervals (HDP) and the significance of the parameter. In all of the cases, a $\log _{10}(x+1)$ transformation was applied

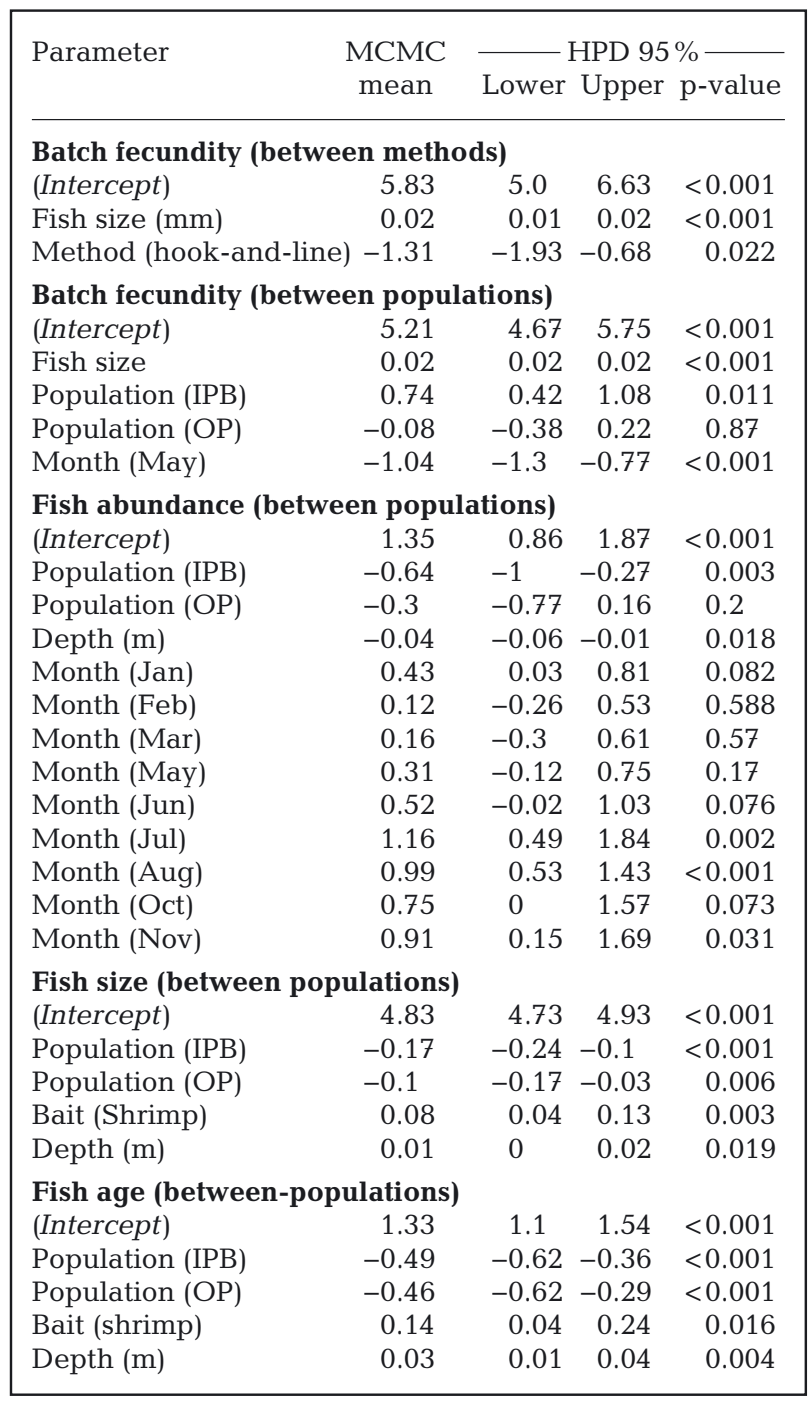

sampled in the IPB had a significantly higher sizecorrected batch fecundity than those sampled in the NPC (GLMM, p < 0.05; Table 2). In terms of abundance and average size and age, the population of IPB was characterised by a significantly lower abun-
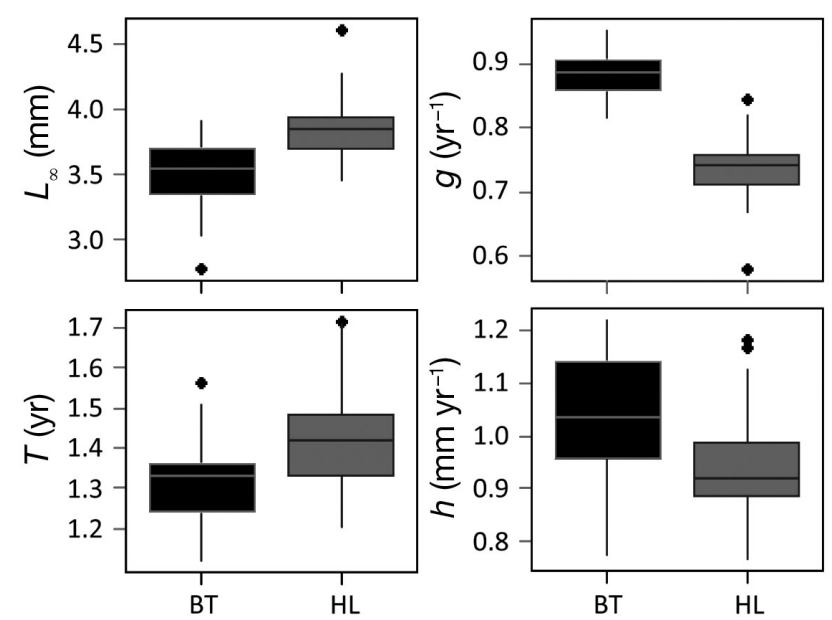

Fig. 5. Box-plot of the individual life-history traits (annual reproduction investment $(g)$, individual maximum theoretical size $\left(L_{\infty}\right)$, age of onset of maturation $(T)$ and immature growth rate $(h)$ estimated for the individuals sampled using the experimental beam trawl (BT) and hook-and-line (HL) methods. Horizontal bars: median; box: 25 and 75 th percentiles of the data; whiskers: non-outlier range; diamonds: outliers
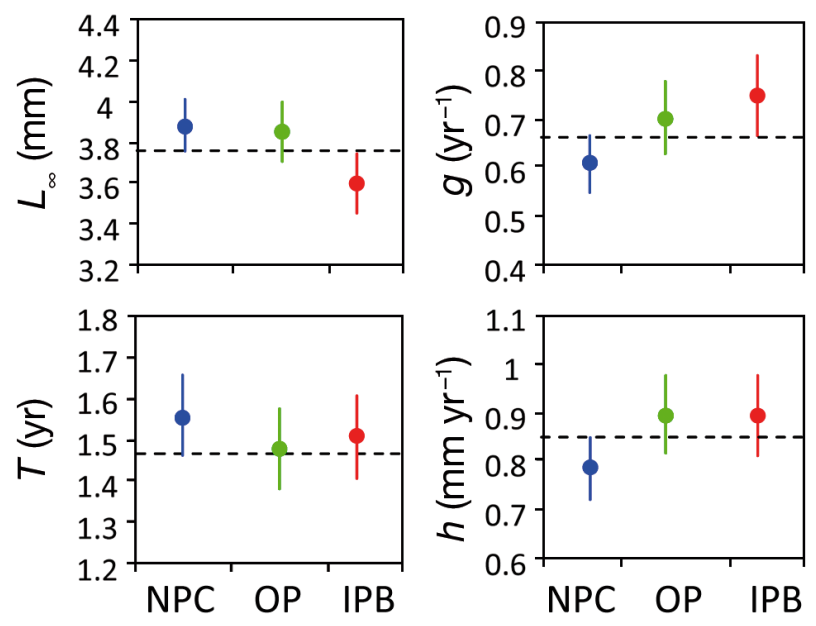

Fig. 6. Bayesian means (colored dots) and credibility intervals (2.5 and $97.5 \%$, colored vertical bars) of the posterior distribution of the population means estimated for each lifehistory trait to assess the differences among sub-populations: the inner part of Palma Bay (IPB) in red, the open population $(\mathrm{OP})$ in green and the National Park of Cabrera (NPC) in blue

dance (as inferred based on angling catch rate), and the fish were on average smaller and younger (Table 2).

In terms of environmental co-variates, the temperature oscillated in the same way on a daily and seasonal basis in the IPB and NPC sites, suggesting no differences in temperature regimes (Fig. 7). This finding was to be expected due to the close proximity between the 2 areas. By contrast, chlorophyll a con- 

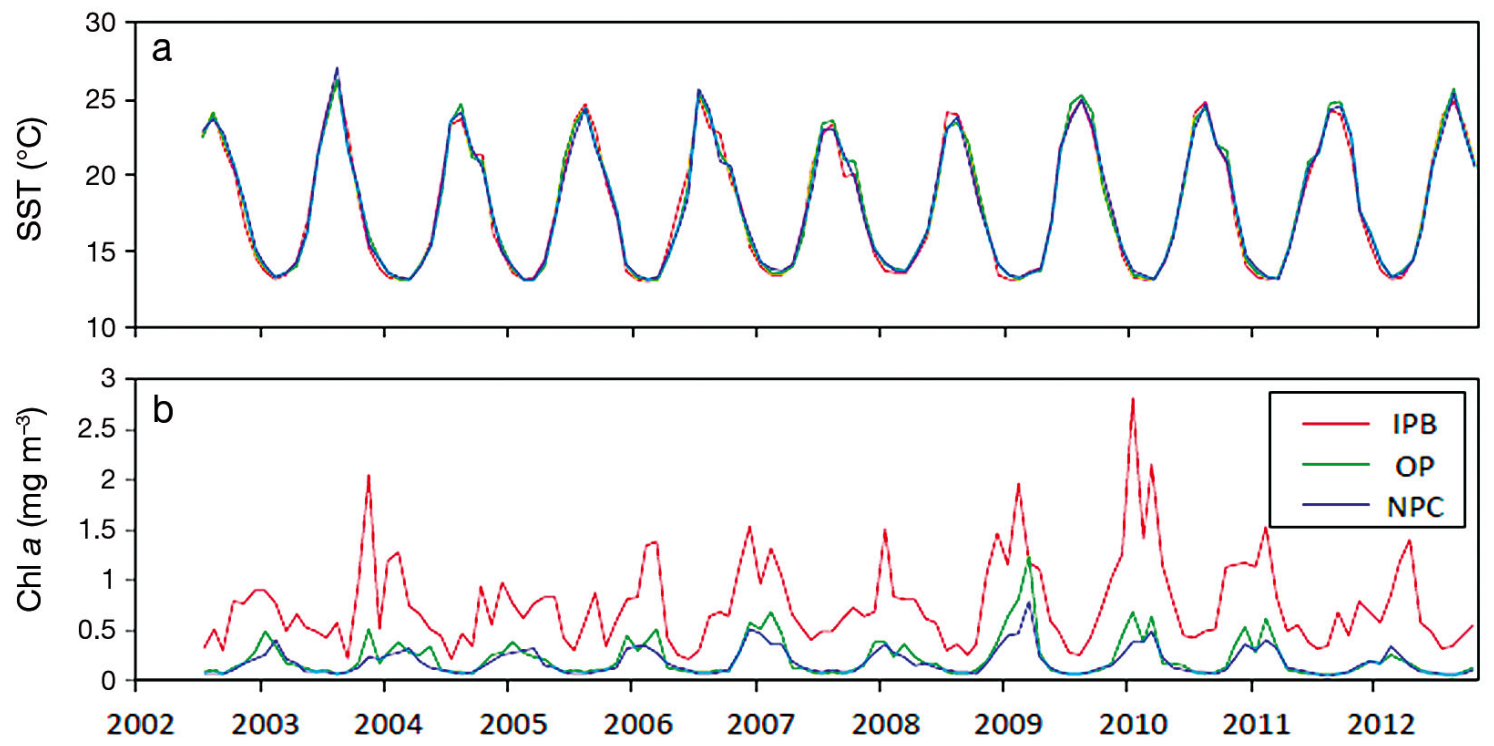

Fig. 7. Chronograms of $10 \mathrm{yr}$ of the sea surface temperature (SST) and concentration of chlorophyll a in the inner part of Palma Bay (IPB, in red), the open population (OP, in green) and the National Park of Cabrera (NPC, in blue)

centrations estimated from the sea-colour images available for the IPB and NPC showed a clear seasonal periodicity in both cases, and the IPB had higher values, suggesting that the IPB was a more productive site than the NPC (Fig. 7). Therefore, one would have expected larger bodied adults in the IPB sites due to elevated resources, but the opposite was found in our study.

\section{DISCUSSION}

We have shown that recreational angling operates non-randomly on Serranus scriba, preferentially capturing individuals with low reproductive investment and high adult body size. Therefore, one would expect a selective response toward increased average reproductive investment and a decline in terminal body length in exploited stocks, which agreed with empirical observations in the highly exploited IPB site compared to the marine protected area. Considering the limited dispersal of adult S. scriba (March et al. 2010), the limited connectivity of early lifestages demonstrated through the particle modelling in our study and the selective nature of intensive recreational angling, we can explain the phenotypic variation observed in different sites in the wild. Based on our data, we propose that trait-selective and intensive recreational angling exploiting metapopulations of $S$. scriba constitute a potential mechanism that contributes to the decline of adult body length in heavily exploited coastal populations. The decline of the adult body size can have negative implications for the productivity and biomass of fish stocks (Jørgensen et al. 2007, Audzijonyte et al. 2013b). Both selective fishing and meta-population structure are, therefore, important to consider when managing coastal populations that are exploited by recreational anglers.

We demonstrated that recreational angling leads to adaptive changes in adult body size by selectively targeting fish with low reproductive investment. These findings are in agreement with theoretical models and empirical data that found that size-selective recreational fishing leads to the evolution of high reproductive investment and small maximum body length (Arlinghaus et al. 2009, Saura et al. 2010, Kendall \& Quinn 2011). Such effects have been well recognized in size-selective commercial fisheries (Jørgensen et al. 2007, Audzijonyte et al. 2013b), and they can have negative implications for the utility that stocks provide to society (Eikeset et al. 2013, Laugen et al. 2014). We propose that recreational angling leads to lowered body size of adult stages similar to effects previously reported in size-selective commercial fisheries.

A particularly novel methodological aspect of our work was related to the fitting of individual growth curves, which resulted in the derivation of individual-level life-history traits that were largely independent of the individual's size at sampling. Deriving life-history traits other than growth rate, e.g. reproductive investment, from an individual growth trajectory has only rarely been used in the literature 
on fisheries-induced evolution (Mollet et al. 2010, Brunel et al. 2013). Our methodological approach should be useful for more long-lived species because the back-constructed individual growth curve can more easily be estimated for such species than for the short-lived species we studied.

We have focused our work on life-history traits, but our approach cannot answer whether fishing directly selects life history or whether there is indirect selection through a correlated response to selection on other traits. Vulnerability to fishing gear is a complex process where correlated life-history, and behavioural and physiological traits constitute the 'vulnerability phenotype' (Uusi-Heikkilä et al. 2008). Fish behaviour plays a major, yet underappreciated, role in the selection process in recreational angling. For example, bold and aggressive fish are, possibly independent of body size, more prone to attack and are more likely to ingest angling baits than shy and less aggressive fish (e.g. Klefoth et al. 2012, 2013, Sutter et al. 2012). Using an individual-based model calibrated to the exploratory behaviour of Serranus scriba, we have demonstrated negative selection differentials on exploration (Alós et al. 2012). Specific behavioural types are correlated with life-history productivity (Biro \& Stamps 2008). We propose that recreational angling-induced selection directly acts on feeding and activity-related behavioural traits, which are correlated with life-history traits in $S$. scriba, in turn leading to a selection response in the correlated life history through selection on behaviour. This selective process should drive exploited populations of S. scriba to become less bold, less aggressive and less explorative in addition to evolving a smaller adult body size, as implicated in our study.

In direct contrast to the direction of recreational fishing-induced selection, natural selection should drive meta-populations of Serranus scriba in the opposite direction by favouring large investments in rapid growth to outgrow gape-size-limited predators. That is, in environments where the abundance of natural predators of S. scriba is high, smaller individuals will experience a greater likelihood of death, in turn yielding selection for large body size and fast growth (see Edeline et al. 2007 for an example in northern pike Esox lucius). The optimal life-history strategy under predation risk in a natural environment should, therefore, imply low reproductive investment and large body sizes (Reznick 1982, Hutchings 1993, Edeline et al. 2007, Olsen \& Moland 2011) to maximize life-time fitness (Roff 1984, Charnov 2005). The wild populations we studied directly confirmed to these expectations. On one hand, $S$. scriba inhabiting the highly exploited sites had life histories characterized by large reproductive investment (estimated both directly and indirectly through batch fecundity and the life-history parameter $g$ ) and small maximum adult body size. On the other hand, the individuals sampled in the no-take area were dominated by phenotypes with a greater capability of achieving large size by investing less energy into reproduction. These between-population results were supported by the 'average' results observed in the open population studied. We can therefore explain the phenotypic variation of the populations of $S$. scriba by the nature of the natural and fisheriesinduced selective process acting on the life histories. Note that our individual methodological approach allows us to explain the decline of the adult body size in the exploited population as stemming from selection acting on life-history traits rather than as a result of demographic truncation and gear-dependent sizeselectivity.

One important aspect of any comparative study such as the one performed here is to address any nonfishing-related environmental drivers that might also explain the among-site variation in life history (Dunlop et al. 2005, Kendall \& Quinn 2011). In fact, all of the differences observed in the life history in our subpopulations could be related to unaccounted environmental characteristics (McDermid et al. 2010). While we cannot discount that the phenotypic change may be entirely environmentally related, the bulk of the evidence presented here makes this explanation unlikely. First, we could discard the hypothesis of substantial variation in temperature among our sites. The only environmental driver that varied between the high- and no-take sites was the greater productivity of the exploited system, as inferred from chlorophyll data. Greater resource availabilities can plastically increase annual reproduction investments due to greater resource intake (e.g. Craig \& Kipling 1983). However, one would then also expect faster growth rates of both immature and mature individuals in the more productive high-exploitation system. Moreover, the reduced density of fish due to exploitation should also elevate growth due to relaxed competition (Lorenzen \& Enberg 2002). In fact, we found fewer fish in the protected site, as revealed by hook and line catch rate data. Even if these data are biased due to lower vulnerability of fish to capture in the exploited site (Klefoth et al. 2013), the higher productivity should still result in faster growth. As a result, the maximum adult body size should correspondingly increase in the exploited sites if only plastic responses were at play (McDermid et al. 2010, Wright et al. 
2011). However, we observed directly opposing patterns. First, the immature growth rates $(h)$ did not differ statistically among the sites, and second, the adult body size was significantly smaller in the high-exploitation sites, although the environmental plasticity hypothesis should have predicted large adult body size. There is no other obvious environmental factor that may explain the life-history difference, rendering fisheries-induced adaptive change a parsimonious mechanism of life-history differentiation.

Providing conclusive cause-and-effect evidence for evolutionary changes in the wild induced by harvesting is currently not possible (Enberg et al. 2012, Audzijonyte et al. 2013a). In fact, whether adaptive changes in life histories are evolutionary or merely indicative of phenotypic plasticity is still under debate for most of the studied commercial populations (Browman et al. 2008, Jørgensen et al. 2008). A range of approaches has been put forward to study fisheries-induced evolution. Theoretical modelling of fisheries-induced evolution (e.g. Arlinghaus et al. 2009, Dunlop et al. 2009) has shown that recreational fishing exploitation can be strong enough to cause selection differentials and for fisheries-induced evolution to be plausible. Naturally, inference of models to the wild is limited, and models will also never conclusively answer whether evolution has truly happened in nature (Audzijonyte et al. 2013a). Many observational studies using time series of phenotypic data from the wild have been conducted to test evidence for fisheries-induced evolution (Audzijonyte et al. 2013a). However, such long time series are very scarce in species with low importance for commercial fisheries such as Serranus scriba. There have been a few observational studies that have used molecular techniques suggesting that genetic change has taken place in response to fishing (Ãrnason et al. 2009, Jakobsdóttir et al. 2011, Pukk et al. 2013), but any genetic information for S. scriba is still missing. A final approach to studying fisheries-induced evolution is observing experimental evolution under controlled conditions (e.g. Conover \& Munch 2002, Conover \& Baumann 2009, Philipp et al. 2009). The strength of these studies is that they can provide cause-and-effect evidence and demonstrate that phenotypic change has a genetic basis, but inference of the observations to the wild is limited.

Comparative field studies such as ours may provide a useful compromise to study whether fishing differentially targets certain phenotypes and whether populations with common ancestry and low current gene flow differ in their average phenotype in directions expected from theory and in line with selection dif- ferentials estimated in the wild (e.g. Drake et al. 1997, Bevacqua et al. 2012). Therefore, based on our study, one should consider the plausibility for fishery-induced genetic change in exploited populations of Serranus scriba. We demonstrated selective harvesting in relation to underlying productivity-related life-history traits, which usually have at least a modest heritability (Law 2000). We also provided evidence for limited population connectivity, which likely leads to limited gene flow in S. scriba. Often, the large effective population size of marine fish has been proposed to constitute barriers to fisheriesinduced evolution (Cuveliers et al. 2011). We have shown, however, that meta-populations of the small coastal species $S$. scriba may develop reproductively isolated sub-populations on small spatial scales, which are characterised by high levels of local selfrecruitment and low direct and indirect connectivity with each other. These findings are in line with recent literature indicating that local hydrodynamics and life history may also result in fine meta-population structures with limited gene flow in many marine areas (Mora \& Sale 2002, Carreras-Carbonell et al. 2007, Galarza et al. 2009). Although we cannot conclusively differentiate between the possibilities of plastic adaptive change or evolutionary adaptation in life history, our study justifies the plausible hypothesis that fisheries-induced genetic change might happen in spatially structured coastal species targeted by recreational angling on very small geographical scales. This occurs because whenever there is no contemporary natural gene flow among sub-populations, differential selection pressures should generate sub-populations that adapt their life histories to the local selective pressures (Reznick et al. 1990).

A potentially fruitful avenue of research for disentangling genetic changes from environmental responses to explain the origin of the decline of body size in Serranus scriba would be to compare the lifehistory traits of the offspring of the different populations reared under identical environmental conditions (Conover \& Baumann 2009). Until such research becomes available, our study proposes a new paradigm of the potential for widespread fisheriesinduced evolution of small-bodied coastal fishes at small scales. Due the potential negative effects of fisheries-induced evolution, which may negatively affect productivity, recovery and catch per unit effort of the stock (Sutter et al. 2012, Audzijonyte et al. 2013b), managers may adjust their management polices to prevent or decrease the selective impacts of harvesting for successful fish-stock management (Walsh et al. 2006). 
Acknowledgements. The present study was partially financed by the research project CONFLICT (grant no. CGL200800958) and REC2 (grant no. CTM2011-23835), both funded by the Spanish Ministry of Economy and Competiveness (MINECO). J.A. was supported by an FPI fellowship (MINECO), and A.J. was supported by a Ramón y Cajal grant (MIMECO). We specially thank the numerous researchers involved in the field work, especially M. Linde, D. March and M. Cabanellas. We also thank the people of the National Park of Cabrera (sampling was performed within the framework of the research project ROQUER grant no. CTM2005-00283). R.A. received funding from the German Federal Ministry for Education and Research (BMBF) through the Program for Social-Ecological Research for the project Besatzfisch (grant no. 01UU0907, www.besatz-fisch. de). The finalization of the study was made possible by the BTypes project funded through the Leibniz Competition (SAW-2013-IGB-2) to R.A. and a Marie Curie Post Doc grant to J.A. (FP7-PEOPLE-2012-IEF, grant no. 327160). We thank the 2 anonymous reviewers for their comments on an early version of the manuscript.

\section{LITERATURE CITED}

> Allendorf FW, Hard JJ (2009) Human-induced evolution caused by unnatural selection through harvest of wild animals. Proc Natl Acad Sci USA 106:9987-9994

Allendorf FW, England PR, Luikart G, Ritchie PA, Ryman N (2008) Genetic effects of harvest on wild animal populations. Trends Ecol Evol 23:327-337

> Alonso-Fernández A, Alós J, Grau A, Dominguez-Petit R, Saborido-Rey F (2011) The use of histological techniques to study the reproductive biology of the hermaphroditic Mediterranean fishes Coris julis, Serranus scriba, and Diplodus annularis. Mar Coast Fish 3:145-159

> Alós J, Arlinghaus R (2013) Impacts of partial marine protected areas on coastal fish communities exploited by recreational angling. Fish Res 137:88-96

Alós J, Arlinghaus R, Palmer M, March D, Alvarez I (2009) The influence of type of natural bait on fish catches and hooking location in a mixed-species marine recreational fishery, with implications for management. Fish Res 97: 270-277

Alós J, Palmer M, Balle S, Grau AM, Morales-Nin B (2010) Individual growth pattern and variability in Serranus scriba: a Bayesian analysis. ICES J Mar Sci 67:502-512

> Alós J, Palmer M, Arlinghaus R (2012) Consistent selection towards low activity phenotypes when catchability depends on encounters among human predators and fish. PLoS ONE 7:e48030

Alós J, Alonso-Fernández A, Catalan I, Palmer M, LowerreBarbieri S (2013) Reproductive output traits of the simultaneous hermaphrodite Serranus scriba in the Western Mediterranean. Sci Mar 77:331-340

> Arlinghaus R, Matsumura S, Dieckmann U (2009) Quantifying selection differentials caused by recreational fishing: development of modeling framework and application to reproductive investment in pike (Esox lucius). Evol Appl 2:335-355

> Ãrnason E, Hernandez UB, Kristinsson K (2009) Intense habitat-specific fisheries-induced selection at the molecular Pan I Locus predicts imminent collapse of a major Cod fishery. PLoS ONE 4:e5529

Audzijonyte A, Kuparinen A, Fulton EA (2013a) How fast is fisheries-induced evolution? Quantitative analysis of modelling and empirical studies. Evol Appl 6:585-595

Audzijonyte A, Kuparinen A, Gorton R, Fulton EA (2013b) Ecological consequences of body size decline in harvested fish species: positive feedback loops in trophic interactions amplify human impact. Biol Lett 9:20121103

> Basterretxea G, Jordi A, Catalán IA, Sabatés A (2012) Model-based assessment of local-scale fish larval connectivity in a network of marine protected areas. Fish Oceanogr 21:291-306

Bevacqua D, Capoccioni F, Melià P, Vincenzi S, Pujolar JM, De Leo GA, Ciccotti E (2012) Fishery-induced selection for slow somatic growth in European eel. PLoS ONE 7 : e37622

> Biro PA, Stamps JA (2008) Are animal personality traits linked to life-history productivity? Trends Ecol Evol 23: 361-368

Browman HI, Law R, Marshall CT (2008) The role of fisheries-induced evolution. Science 320:47-50

> Brunel T, Ernande B, Mollet FM, Rijnsdorp AD (2013) Estimating age at maturation and energy-based life-history traits from individual growth trajectories with nonlinear mixed-effects models. Oecologia 172:631-643

- Cabanellas-Reboredo M, Alós J, Palmer M, March D, Dor R (2012) Movement patterns of the European squid Loligo vulgaris during the inshore spawning season. Mar Ecol Prog Ser 466:133-144

> Carreras-Carbonell J, Macpherson E, Pascual M (2007) High self-recruitment levels in a Mediterranean littoral fish population revealed by microsatellite markers. Mar Biol 151:719-727

Casabianca S, Penna A, Pecchioli E, Jordi A, Basterretxea G, Vernesi C (2012) Population genetic structure and connectivity of the harmful dinoflagellate Alexandrium minutum in the Mediterranean Sea. Proc R Soc Lond B Biol Sci 279:129-138

Charnov EL (2005) Reproductive effort is inversely proportional to average adult life span. Evol Ecol Res 7: 1221-1222

Conover DO, Baumann H (2009) The role of experiments in understanding fishery-induced evolution. Evol Appl 2: 276-290

> Conover DO, Munch SB (2002) Sustaining fisheries yields over evolutionary time scales. Science 297:94-96

> Cooke SJ, Suski CD, Ostrand KG, Wahl DH, Philipp DP (2007) Physiological and behavioral consequences of long-term artificial selection for vulnerability to recreational angling in a teleost fish. Physiol Biochem Zool 80:480-490

Cowen RK, Paris CB, Srinivasan A (2006) Scaling of connectivity in marine populations. Science 311:522-527

> Craig JF, Kipling C (1983) Reproduction effort versus the environment; case histories of windermere perch, Perca fluviatilis L., and pike, Esox lucius L. J Fish Biol 22: 713-727

> Cuveliers EL, Volckaert FAM, Rijnsdorp AD, Larmuseau MHD, Maes GE (2011) Temporal genetic stability and high effective population size despite fisheries-induced life-history trait evolution in the North Sea sole. Mol Ecol 20:3555-3568

> Deudero S, Morey G, Frau A, Moranta J, Moreno I (2008) Temporal trends of littoral fishes at deep Posidonia oceanica seagrass meadows in a temperate coastal zone. J Mar Syst 70:182-195

> Drake MT, Claussen JE, Philipp DP, Pereira DL (1997) A comparison of bluegill reproductive strategies and 
growth among lakes with different fishing intensities. N Am J Fish Manag 17:496-507

> Dunlop ES, Orendorff JA, Shuter BJ, Rodd FH, Ridgway MS (2005) Diet and divergence of introduced smallmouth bass (Micropterus dolomieu) populations. Can J Fish Aquat Sci 62:1720-1732

> Dunlop ES, Baskett ML, Heino M, Dieckmann U (2009) Propensity of marine reserves to reduce the evolutionary effects of fishing in a migratory species. Evol Appl 2: 371-393

Edeline E, Carlson SM, Stige LC, Winfield IJ and others (2007) Trait changes in a harvested population are driven by a dynamic tug-of-war between natural and harvest selection. Proc Natl Acad Sci USA 104:15799-15804

> Eikeset AM, Richter A, Dunlop ES, Dieckmann U, Stenseth NC (2013) Economic repercussions of fisheries-induced evolution. Proc Natl Acad Sci USA 110:12259-12264

- Ellison AM (2004) Bayesian inference in ecology. Ecol Lett 7: 509-520

> Enberg K, Jørgensen C, Dunlop ES, Varpe $\varnothing$ and others (2012) Fishing-induced evolution of growth: concepts, mechanisms and the empirical evidence. Mar Ecol 33: $1-25$

Francour P, Harmelin JG, Pollard D, Sartoretto S (2001) A review of marine protected areas in the northwestern Mediterranean region: siting, usage, zonation and management. Aquat Conserv 11:155-188

> Galarza JA, Carreras-Carbonell J, Macpherson E, Pascual M, Roques S, Turner GF, Rico C (2009) The influence of oceanographic fronts and early-life-history traits on connectivity among littoral fish species. Proc Natl Acad Sci USA 106:1473-1478

Heino M, Godo OR (2002) Fisheries-induced selection pressures in the context of sustainable fisheries. Bull Mar Sci 70:639-656

- Heino M, Baulier L, Bouka DS, Ernande B and others (2013) Can fisheries-induced evolution shift reference points for fisheries management? ICES J Mar Sci 70:707-721

Hutchings JA (1993) Adaptive life histories effected by agespecific survival and growth rate. Ecology 74:673-684

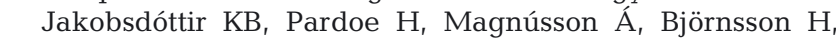
Pampoulie C, Ruzzante DE, Marteinsdóttir G (2011) Historical changes in genotypic frequencies at the Pantophysin locus in Atlantic cod (Gadus morhua) in Icelandic waters: evidence of fisheries-induced selection? Evol Appl 4:562-573

> Johnston FD, Arlinghaus R, Dieckmann U (2013) Fish life history, angler behaviour and optimal management of recreational fisheries. Fish Fish 14:554-579

> Jones GP, Planes S, Thorrold SR (2005) Coral reef fish larvae settle close to home. Curr Biol 15:1314-1318

> Jørgensen C, Fiksen O (2009) Modelling fishing-induced adaptations and consequences for natural mortality. Can J Fish Aquat Sci 67:1086-1097

> Jørgensen C, Holt RE (2013) Natural mortality: its ecology, how it shapes fish life histories, and why it may be increased by fishing. J Sea Res 75:8-18

> Jørgensen C, Enberg K, Dunlop ES, Arlinghaus R and others (2007) Managing evolving fish stocks. Science 318: 1247-1248

> Jørgensen C, Enberg K, Dunlop ES, Arlinghaus R and others (2008) Managing evolving fish stocks (Response). Science 320:48-50

Kendall NW, Quinn TP (2011) Length and age trends of Chinook salmon in the Nushagak River, Alaska, related to commercial and recreational fishery selection and exploitation. Trans Am Fish Soc 140:611-622

Klefoth T, Skov C, Krause J, Arlinghaus R (2012) The role of ecological context and predation risk-stimuli in revealing the true picture about the genetic basis of boldness evolution in fish. Behav Ecol Sociobiol 66:547-559

Klefoth T, Pieterek T, Arlinghaus R (2013) Impacts of domestication on angling vulnerability of common carp (Cyprinus carpio L.): the role of learning, foraging behaviour and food preferences. Fish Manag Ecol 20:174-186

Kough AS, Paris CB, Butler MJ (2013) Larval connectivity and the international management of fisheries. PLoS ONE 8:e64970

> Kuparinen A, Merilä J (2007) Detecting and managing fisheries-induced evolution. Trends Ecol Evol 22:652-659

Laugen AT, Engelhard GH, Whitlock R, Arlinghaus R and others (2014) Evolutionary impact assessment: accounting for evolutionary consequences of fishing in an ecosystem approach to fisheries management. Fish Fish 15: 65-96

Law R (2000) Fishing, selection, and phenotypic evolution. ICES J Mar Sci 57:659-668

- Lester NP, Shuter BJ, Abrams PA (2004) Interpreting the von Bertalanffy model of somatic growth in fishes: the cost of reproduction. Proc R Soc Lond B Biol Sci 271:1625-1631

Lorenzen K, Enberg K (2002) Density-dependent growth as a key mechanism in the regulation of fish populations: evidence from among-population comparisons. Proc R Soc Lond B Biol Sci 269:49-54

> Macpherson E, Raventos N (2006) Relationship between pelagic larval duration and geographic distribution of Mediterranean littoral fishes. Mar Ecol Prog Ser 327: 257-265

March D, Palmer M, Alós J, Grau A, Cardona F (2010) Shortterm residence, home range size and diel patterns of the painted comber Serranus scriba in a temperate marine reserve. Mar Ecol Prog Ser 400:195-206

> Matsumura S, Arlinghaus R, Dieckmann U (2011) Assessing evolutionary consequences of size-selective recreational fishing on multiple life-history traits, with an application to northern pike (Esox lucius). Evol Ecol 25: 711-735

> McDermid JL, Shuter BJ, Lester NP (2010) Life history differences parallel environmental differences among North American lake trout (Salvelinus namaycush) populations. Can J Fish Aquat Sci 67:314-325

Mollet FM, Ernande B, Brunel T, Rijnsdorp AD (2010) Multiple growth-correlated life history traits estimated simultaneously in individuals. Oikos 119:10-26

> Mora C, Sale PF (2002) Are populations of coral reef fish open or closed? Trends Ecol Evol 17:422-428

Morales-Nin B, Moranta J, Garcia C, Tugores MP, Grau AM, Riera F, Cerda M (2005) The recreational fishery off Majorca Island (western Mediterranean): some implications for coastal resource management. ICES J Mar Sci 62:727-739

- Moranta J, Palmer M, Morey G, Ruiz A, Morales-Nin B (2006) Multi-scale spatial variability in fish assemblages associated with Posidonia oceanica meadows in the Western Mediterranean Sea. Estuar Coast Shelf Sci 68: 579-592

Olsen E, Moland E (2011) Fitness landscape of Atlantic cod shaped by harvest selection and natural selection. Evol Ecol 25:695-710

Olsen EM, Heino M, Lilly GR, Morgan MJ, Brattey J, Ernande 
B, Dieckmann U (2004) Maturation trends indicative of rapid evolution preceded the collapse of northern cod. Nature 428:932-935

Palumbi SR, Warner RR (2003) Why gobies are like hobbits. Science 299:51-52

Pelc RA, Warner RR, Gaines SD, Paris CB (2010) Detecting larval export from marine reserves. Proc Natl Acad Sci USA 107:18266-18271

Philipp DP, Cooke SJ, Claussen JE, Koppelman JB, Suski CD, Burkett DP (2009) Selection for vulnerability to angling in Largemouth Bass. Trans Am Fish Soc 138:189-199

Pilling GM, Kirkwood GP, Walker SG (2002) An improved method for estimating individual growth variability in fish, and the correlation between von Bertalanffy growth parameters. Can J Fish Aquat Sci 59:424-432

Plummer M, Best N, Cowles K, Vines K (2006) CODA: convergence diagnosis and output analysis for MCMC. R News 6:7-11

Pukk L, Kuparinen A, Järv L, Gross R, Vasemägi A (2013) Genetic and life-history changes associated with fisheries-induced population collapse. Evol Appl 6:749-760

Quince C, Abrams PA, Shuter BJ, Lester NP (2008a) Biphasic growth in fish. I. Theoretical foundations. J Theor Biol 254:197-206

Quince C, Shuter BJ, Abrams PA, Lester NP (2008b) Biphasic growth in fish. II. Empirical assessment. J Theor Biol 254:207-214

> Redpath TD, Cooke SJ, Arlinghaus R, Wahl DH, Philipp DP (2009) Life-history traits and energetic status in relation to vulnerability to angling in an experimentally selected teleost fish. Evol Appl 2:312-323

Redpath TD, Cooke SJ, Suski CD, Arlinghaus R, Couture P, Wahl DH, Philipp DP (2010) The metabolic and biochemical basis of vulnerability to recreational angling after three generations of angling-induced selection in a teleost fish. Can J Fish Aquat Sci 67:1983-1992

Reñones O, Goñi R, Pozo M, Deudero S, Moranta J (1999) Effects of protection on the demographic structure and abundance of Epinephelus marginatus (Lowe, 1834). Evidence from Cabrera Archipelago National Park (West-central Mediterranean). Mar Life 9:45-53

Reznick D (1982) The impact of predation on life history evolution in Trinidadian guppies: genetic basis of observed life history patterns. Evolution 36:1236-1250

Reznick DA, Bryga H, Endler JA (1990) Experimentally induced life-history evolution in a natural population. Nature 346:357-359

Roberts CM (1997) Connectivity and management of Carib-

Editorial responsibility: Konstantinos Stergiou,

Thessaloniki, Greece bean coral reefs. Science 278:1454-1457

Roff DA (1984) The evolution of life history parameters in teleosts. Can J Fish Aquat Sci 41:989-1000

- Saura M, Moran P, Brotherstone S, Caballero A, Alvarez J, Villanueva B (2010) Predictions of response to selection caused by angling in a wild population of Atlantic salmon (Salmo salar). Freshw Biol 55:923-930

- Shuter BJ, Lester NP, LaRose J, Purchase CF and others (2005) Optimal life histories and food web position: linkages among somatic growth, reproductive investment, and mortality. Can J Fish Aquat Sci 62:738-746

Stinchcombe JR, Kirkpatrick M (2012) Genetics and evolution of function-valued traits: understanding environmentally responsive phenotypes. Trends Ecol Evol 27: 637-647

Sutter DAH, Suski CD, Philipp DP, Klefoth T and others (2012) Recreational fishing selectively captures individuals with the highest fitness potential. Proc Natl Acad Sci USA 109:20960-20965

> Swain DP, Sinclair AF, Mark Hanson J (2007) Evolutionary response to size-selective mortality in an exploited fish population. Proc R Soc Lond B 274:1015-1022

> Teacher AGF, André C, Jonsson PR, Merilä J (2013) Oceanographic connectivity and environmental correlates of genetic structuring in Atlantic herring in the Baltic Sea. Evol Appl 6:549-567

> Uusi-Heikkilä S, Wolter C, Klefoth T, Arlinghaus R (2008) A behavioral perspective on fishing-induced evolution. Trends Ecol Evol 23:419-421

> Walsh MR, Munch SB, Chiba S, Conover DO (2006) Maladaptive changes in multiple traits caused by fishing: impediments to population recovery. Ecol Lett 9:142-148

Walters C, Martell SJD (2004) Fisheries ecology and management. Princeton University Press, Princeton, NJ

> Watson JR, Hays CG, Raimondi PT, Mitarai S and others (2011) Currents connecting communities: nearshore community similarity and ocean circulation. Ecology 92: 1193-1200

Wilson ADM, Binder TR, McGrath KP, Cooke SJ, Godin JGJ (2011) Capture technique and fish personality: angling targets timid bluegill sunfish, Lepomis macrochirus. Can J Fish Aquat Sci 68:749-757

> Wright PJ, Millar CP, Gibb FM (2011) Intrastock differences in maturation schedules of Atlantic cod, Gadus morhua. ICES J Mar Sci 68:1918-1927

Zuur AF, Leno EN, Walker NJ, Saveliev AA, Smith GM (2009) Mixed effects models and extensions in ecology with R. Springer-Verlag, New York, NY

Submitted: October 31, 2013; Accepted: January 25, 2014 Proofs received from author(s): April 8, 2014 